\title{
More than Human Nature and the Open Space Predicament
}

Green and open spaces figured prominently in imaginative exercises in urban redesign, and they also provided a variable, an empirical indicator for the environmental success or failure of the Mumbai of the future. Assuming even distribution and access, two conditions almost never met in practice, the logic of open space seemed to offer a comprehensive bridge between ecological improvement and social justice. It seemed logically and automatically connected to promoting biodiversity habitat, better and cleaner water systems, improved coastal resilience and drainage control, better air quality, and a host of leisure opportunities for inhabitants of a population-dense city struggling for "breathing space;" these would all enhance human well-being. Here was a model for a "truly integrated" urban environment, one left unserved by the development trajectory of Mumbai's contemporary history.

Anchoring collective hope for an improved city to an idealized vision of social and environmental vitality is neither novel nor surprising; in fact, precisely such visions feature in sustainable city thinking worldwide. The presence and absence of green and open spaces-be they parks, urban gardens, urban forests and conservation areas, or expressed as the simple percentage of city land that is not built up-is ubiquitous in conventional assessments of relative environmental vitality. However, as I will show in this chapter, those same spaces present an analytical challenge to theoretical and in-practice logics of environmental justice, integrated socio-nature, and the modes of social identity reproduction fundamental to the social life of urban open spaces. At the core of this challenge is, yet again, the idea of the environment as an integrated subject, as it is precisely the integration 
gesture that confounds our best attempts to simultaneously understand human and nonhuman transformation.

\section{PRESERVATION, SCIENCE, AND EQUITY: ECOLOGY AND THE ANTI-PUBLIC}

A shared element of each event described in the previous chapter, and a general characteristic of contemporary middle class assumptions about desirable, livable cities with ecological integrity was the presence of plentiful open spaces, also referred to as urban open or urban green space. Generally, these terms can encompass everything from abandoned urban lots to dense urban forest stands. Together they have come to occupy an automatic place in regional and global conversations about desirable aspects of sustainable future cities.

Indices like the ratio, distribution, and scale of available open spaces often figure prominently in environmental policy objective-setting, and together with concerns about climate resilience, water and air quality, energy provision, and circuits of waste, these have become standard elements in regional and global assessments of relative urban environmental quality and performance. ${ }^{1}$ In turn, they are often used as indicators of overall human well-being in urban contexts. ${ }^{2}$

Challenges to assumptions that more open spaces beget greater social equity abound; recent social science scholarship in Indian cities like Delhi and Mumbai reminds us afresh that the lived experience of urban open spaces is more often one of social exclusion, not inclusion. ${ }^{3}$ This literature enumerates injustices and violence that may be socially legitimized precisely because of the place of green spaces in global and more locally active ideologies of open space entitlement. A broad literature also shows that expectations for certain modes of sociality and "civility" often accompany the regulation of such spaces, rendering them anything but open access. ${ }^{4}$

Global open space narratives and metrics are also known to obfuscate the complex local social processes through which access to such spaces is socially policed, calling into question assumptions that open spaces provide automatic benefits regardless of one's prior place in various strata of social difference. The nevertheless persistent "greater common environmental good" idea, famously reinforced in the classic work that defined sustainable development for the international policy community in the nineteen eighties, Our Common Future, continues to enable exclusive and often unjust environmental policies in the name of, and with the intention of, promoting social equity.

For the many who deem the social inequities that can accompany urban open space creation unacceptable, but who are nevertheless committed to forging a more equitable balance between a city's material built form and its vital biophysical processes - indeed, for those who, as in the CitiSpace explanation of its Breathing Space exhibition, regard open space advocacy as anything but elitist-social equity 
and justice principles must always accompany open space creation. This may mean that so-called urban greening marks an opportunity to open new social avenues for collaboration, advocacy, and consultation among those most marginalized in society. In this way, the provision of access to outdoor, open, safe spaces for leisure activity may be regarded as one of many tools for achieving higher levels of urban social justice.

In planning and policy circles, metrics that capture the proximity of all urban inhabitants, not just elites, to green spaces, and metrics that ensure a specific set of qualities to all of those spaces, are considered useful safeguards against the kinds of greening injustices that may deprive or further marginalize disadvantaged groups. Globally, many cities ratify development plans that are guided in part by target ratios of open space to population. New York City's iconic PlaNYC Sustainable Development Plan, for example, proudly declared its intention to ensure that by its target date of 2030, "all New Yorkers will live within a ten minute walk to a park." Proximity and access to green spaces then, was deemed in the New York case to be as important as the existence of green spaces in the first place. Similarly, in Mumbai, despite the nuances signaled by P.K. Das and Associates' typology of open spaces, the green space category often became shorthand for human usefocused parks, and the majority population's lack of proximity to parks punctuated conversations assessing Mumbai's relative failure to secure a green urban future.

We might draw from this discussion the observation that, in case studies of city park-making, a somewhat polar analytic offers two general clusters of thinking: one notices the very powerful contemporary purchase of opportunities to remake, reclaim, and refashion longstanding patterns of urbanization. Here, to "green" a city, and to engage in "good design," are regarded as acts that promote social empowerment and equity. The second cluster marks the exclusionary and often violent ways that such initiatives are deployed in practice, and describes the social and spatial marginalities they can recreate or newly produce. Here, the social life of urban greening seems to return forms of social exclusion that replicate or reinforce existing power asymmetries in cities. ${ }^{6}$

Notably missing from these two modes of thinking is attention to green or open spaces as a complex category that might contain a range of open space forms, in which each form enables or dissuades particular types and intensities of human and nonhuman "use." If different types of open space perform unique biophysical and social functions, so too will their capacity to generate more socially equitable circumstances vary. Or will they?

In this chapter, I trace a specific instance in which an open space preservation effort raised questions about the category of open space itself, in part through the involvement of an RSIEA professor undertaking precisely the kind of work that, in training, the program promoted as good design. The case follows the analytical concept of more-than-human nature to consider when and how it introduces the problem of more-than-social exclusion. If we differentiate open spaces according 
to their human access profiles, that is, along a continuum of heavy recreational use (a running track, for instance, or a cricket field) to more restricted scenarios of human use (like a relatively dense, closed-canopy forested area), the very question of what urban environmental exclusions do may be recast, and in the process perhaps, urban environmental justice might be rendered more expansive. At issue here is the tendency to assume that most, if not all, urban green or open space worth advocating should serve direct human leisure objectives for as broad a public as possible.

A few months after I arrived in Mumbai, I received a call from a colleague at a major international conservation organization. I have worked in various research capacities with this organization over many years, and I maintain an active interest in, and periodic involvement with, their work in Asia. The call wasn't necessarily a surprise, then, but the purpose behind it was quite unexpected.

After discussing the status of my Mumbai-based research, my colleague asked if I was familiar with what were then recent controversies surrounding the large forest and temple complex in the heart of South Mumbai, the Parsi complex known as the Doongerwadi Forest. ${ }^{7}$ My longstanding interest in the scope and distribution of green or otherwise undeveloped spaces in Mumbai meant that I was keenly aware of this relatively large, fifty-four-acre forested area in Malabar Hill. The forest was established in the seventeenth century as a sacred grove to surround several Parsi Towers of Silence, and so it was an existing urban green space among very few in the city. Yet it was also highly unusual because it was such an old, contiguous, closed-canopy forest-in fact, the only closed-canopy contiguous forest in South Mumbai (and, save Sanjay Gandhi National Park to the north of the city, much of the rest of Mumbai as well). Located in one of the wealthiest and historically most elite parts of the city, it was even more unusual because access to it was restricted exclusively to members of the minority religious group, the Parsis, and even then, only for specific rituals. Although densely vegetated, this was not a park or leisure space; instead, it was a forest whose central purpose was to shelter and seclude the sacred Towers of Silence inside it.

In fact, at that time, the Doongerwadi had gained more recent notoriety as part of an unfolding drama across the Indian subcontient. The controversial use of a relatively new veterinary drug called diclofenac had had observable and catastrophic impacts on South Asia's population of vultures. Use of the drug in livestock, upon whose carcasses vultures naturally feed, was directly linked to the fatal poisoning and a massive die-off of the subcontinental population of gyps vultures. By 2007 , the drug's toxic effects were widely believed to be the primary cause of a dramatic vulture population crash: previously robust regional populations of oriental white-backed vultures had declined to the point of near extinction, and longbilled and slender-billed vulture populations had declined by $97 \% .^{8}$ 
Although banned for veterinary use in 2006, diclofenac remains available for human use, and that availability ensures its persistent, widespread (if illegal) use in veterinary applications. Effective, "vulture safe" alternatives to this drug exist, but none was as inexpensive as diclofenac.

In addition to disrupting basic decomposition patterns in India's livestock, the vultures' disappearance had dramatic consequences for Mumbai's small but historically relatively elite religious group, the Parsis. For centuries, Maharashtra's vultures were the key to funerary rituals prescribed by Zoroastrian (Parsi) religious tradition. In this ritual, Parsi deceased are laid out on high, open platforms in specially constructed enclosures known as Towers of Silence (dokhmas). There, on the sky platform, decomposition takes place through the work of scavenging birds-vultures. As the vulture population crashed, the decomposition process that had functioned for centuries on those platforms was disrupted, and the Towers of Silence in Mumbai harbored more and more deceased whose final funerary rites were disturbed and even halted. Without the rapid decomposition ensured by the vultures, bodies laid atop the towers breaking down only very slowly. The anguish and delicacy of this matter fueled outrage inside and outside of Mumbai's Parsi community, and brought to public consciousness the religious group, their ritual, the function of the towers, and the near-extinction of India's vultures. It also brought to public consciousness the extraordinary urban forest within which this drama was unfolding.

Media coverage tended toward the sensational and the macabre, adding layers of insult and pain to an already wrenching situation in the Parsi community. To the horror of Parsis and non-Parsis alike, news articles graphically described an accumulation of dead in the towers, with no natural catalysts for total decomposition. Seeking alternatives while desperate to maintain the integrity of their life cycle ritual, the community adopted experimental measures. They activated solar collectors atop some of the towers, in hopes of artificially assisting with natural decomposition, with unsatisfactory results. Debates about whether to continue the traditional funerary practices at all ensued, and the degree to which these practices were "modern" was set against the backdrop of an increasingly dire and untenable situation in the towers. The intensity of the debates gave this socioecological story a sense of urgency and purchase far beyond Mumbai, its Parsi community, and the region. Articles in the New York Times and Harper's Magazine, among others, brought the unfolding drama to the attention of readers worldwide. ${ }^{9}$

For as long as the Towers had existed, so too had the Doongerwadi forest that surrounds it. Originally far larger, the contemporary fifty-four-acre closed canopy forest today represents South Mumbai's largest patch of unmanaged and therefore presumably ecologically robust green space. Indeed, it is one of very few spaces in South Mumbai that can qualify in any way as "green." But as noted earlier, this was by no means a green space in the sense of an open access park or leisure space. It was a solemn forest, accessible only to Parsis and even then under very controlled 
circumstances. The Doongerwadi remained a forest over time likely because it sheltered Parsi life cycle rituals. These were sustained in large part by much broader ecological processes, most prominently the vultures and the specific patterns of decomposition their activity enabled. One might argue that the vultures had as much to do with the preservation of this forest area as the presence of the Towers of Silence themselves, or even the strict controls on human access and use beyond visiting for purposes of ritual. The stakes of a grave situation in the vulture population thus extended directly to green space, religious ritual practice, and human identity formation itself.

On the phone, my colleague explained that her organization, which has for decades based a significant portion of its programming on efforts to revitalize endangered animal and plant populations, had taken an interest in the vulture decline in Southern India. She asked if I might consider assisting with a pro bono effort to better understand the green space at the center of the vulture issue: would I be interested in looking at the Doongerwadi forest "as a green space?" That is, could I help to assess the forest's ecological value in a way that bracketed, insofar as was possible, the volatile religious and identity politics issues that had dominated the vulture controversy, and focus instead on the fifty-four acres of forest that surrounded the Towers as an ecosystem in the conventional, exclusively biophysical sense-as a bundle of ecosystem characteristics and services?

She explained further: while conducting advocacy work to mitigate the vulture die-off, some members of the Doongerwadi forest stewardship community had contacted the organization to learn about precisely these qualities. In a sense, they wished to understand the forest "as a valuable open space," but not as a public park or a place of leisure. They wondered how it functioned "as a forest," and whether that function bestowed values on the Doongerwadi beyond those that the community already knew and affirmed. For centuries the forest had been cherished as a sacred grove and a shelter for the Towers of Silence, but the community now wondered how else it might be valued, both among Parsis and by the city at large.

To compound the tensions inside and outside the Parsi community over the loss of vultures and the dysfunction it had wrought, the Doongerwadi forest faced another sort of unprecedented pressure. Over time, and under present conditions of soaring real estate values, any patches of "undeveloped," that is, unbuilt space in South Mumbai assumed astronomical value for developers. The Doongerwadi was no exception, and its coverage in mature forest only increased its already soaring economic value.

In a city rife with real estate deals and speculative investment, this was land with an almost incalculable financial value to developers, and hence, potentially, to the Parsi community. My colleague described a community torn by how to proceed, and understandably concerned that development pressures might eventually produce a more financially stable future, but at the incalculable cost of the total demise of the forest. Those who had contacted the colleague were uninterested in 
selling the land regardless of its real estate value; quite to the contrary, they sought to preserve it, and in doing so work to revive the vulture population. It was crucial, then, that they understand and express alternative ways to value Doongerwadi land, and one of these was clearly its value as urban green space. ${ }^{10}$ My colleague told me that her organization wished to help them understand the forest "as an ecosystem and a natural resource" in order to supplement its known value as a cultural site, or sacred grove, and its estimated economic value as a potential parcel of real estate. ${ }^{11}$

Embedded as it was in Mumbai's historical moment, when the entire cityscape was in some circles being actively reimagined, and given the central role of open space advocacy for motivating public engagement in that moment, I was both intrigued and hesitant. After all, this was a highly exclusive green space. Questions of access, proximity, and claims to use of any kind outside of religious purposes were not the focus here. To assume the task my colleague requested could easily translate into helping to keep the forest socially exclusive; to illustrate its biophysical value would hinge, of course, on the uniqueness of the forest as old, as closed canopy, and as relatively unmanaged, unmanicured, and, in the language of natural resource management, undisturbed. Did I dare play a role in shoring up arguments to keep this forest closed and exclusive? On the other hand, without a set of additional ways to understand and articulate its value, this ecologically and socially significant green space would surely succumb to the power of real estate pressures. These, in the end, could prove far more powerful in present day Mumbai than any political movement to "reimagine" the city.

A great deal of political ecology research shows how scientific discourse is often used to provide falsely "neutral" arbitration in otherwise seemingly intractable socioenvironmental disputes. This left me further weary of assuming the easy role of an outside so-called expert who could give an authoritative account of the value of this urban forest "as a forest." Furthermore, my actual expertise in forest assessment and forest science was limited-a skillset developed only as a graduate student in a handful of courses. I was hardly the specialist who might evaluate and enumerate the species composition, forest health, and specific characteristics that gave the Doongerwadi value beyond its potential as a piece of developable real estate.

And yet I was also keenly aware of the unique set of questions before me. How might we understand this forest as a socionatural green space among open, green spaces that are largely imagined as parks and leisure spaces in Mumbai? Did this represent a chance to foreground the complex biophysical interplay of various types of green spaces, and to amplify their role in urban socioecological vitality? In some ways, I was being asked to participate in a process of literally imagining an alternative future for the Doongerwadi, one guided by an ecological narrative that would reinforce an existing cultural one, and one that would challenge the logic that anticipates urban development as a de facto response to market forces and 
powerful corporate-bureaucratic interests. In other ways, I was being asked to help strengthen a case for reproducing a green space almost completely inaccessible to the vast majority of Mumbai's population. In either scenario, the forest's very existence "as a forest" was clearly at stake. I was once again reminded in an experiential way that there is never such a thing as neutral research.

The narrow band of analytical engagement with green spaces that I recounted above-the prevailing inclination to read them either as opportunities to promote social justice or as spaces inevitably implicated in new forms of social exclusionwas instantly insufficient here. Yes, the Doongerwadi was a highly exclusive forest on grounds rooted in social identity and sacred territory claims. For centuries its interior had been accessible only to select groups of Parsis, but the invitation was now extended to me, to walk the forest with the community's forest steward. I interpreted this as a significant signal of how deeply fraught with urgency this matter, and hence the forest's preservation through reinvention, had become.

Back on the phone, my immediate reply to my colleague was one of gratitude for thinking of me but also a detailed claim that I was not qualified to undertake a forest assessment. Without a baseline evaluation of the species mix, age class, and general health of the trees on the site, additional surveys of the biodiversity mix the area was supporting was not possible. But my colleague had clearly anticipated this response. Suggest a botanist, a forest scientist-suggest the team that would be needed, she quickly offered. The important thing was that I would meet the Doongerwadi forest steward and coordinate a set of formal questions that could serve as the basis of a study. This would then help the community discern the area as a forest. My involvement would get the initiative started, she explained, so that it could assume its own momentum, as determined by the Parsi community.

On learning further that the Bombay Natural History Society, India's Central Zoo Authority, the Ministry of Environment and Forests, and others were already deeply involved in large-scale efforts to reverse vulture extinction trends, my curiosity was piqued. I agreed to meet the forest steward for a walk in the Doongerwadi, nervously conscious of the fact that very few non-Parsis had ever been granted such an invitation. Clearly just by granting me entry, the remaking of this forest area had already begun; my presence in that process might allow me to suggest biodiversity as part of a conversation heretofore focused on vultures, ritual practices, human identity formation, and real estate development. Perhaps it could also add other forms of open space to a civic conversation that often conflated desirable open spaces exclusively with fully accessible parks.

In the days between our phone conversation and my first scheduled visit to the Doongerwadi forest, I studied the vulture conservation initiative proposed by the consortium of ministries and organizations named above. Their projects followed from recommendations made in at least two official plans-the Vulture Action 
Plan of the Government of India (2006) and the South Asian Vulture Recovery Plan (2004). Both of these called for a complete ban on diclofenac and the rapid establishment of vulture breeding facilities.

Since 2006, state governments have set up vulture breeding programs in three Indian states. The Central Zoo Authority also maintains vulture conservation centers at five zoos, but these are not considered effective or highly functional. With fewer than 350 vultures in captivity across all of these centers, the need for additional breeding programs was regarded as critical within the South Asian environmental policy and advocacy community. So critical, in fact, that the Bombay Natural History Society, in partnership with multiple government bodies, proposed to construct two colony aviaries in the Doongerwadi forest, each "attached" to one of the three operational Doongerwadi dokhmas. These would then be linked to another breeding aviary roughly sixty kilometers north of the city, in Sanjay Gandhi National Park at Borivili. This was referred to in project documents as a "Main Center."

Captive breeding and vulture conservation work at Doongerwadi would require an aviary infrastructure that included two vast, completely closed nets suspended at a height of thirty feet (at least twelve feet above the rims of the towers) and surrounding each of the operational dokhmas. In addition, a new complex to house staff and monitoring equipment would be constructed inside the forest. Such a vast complex for vulture rehabilitation infrastructure laid bare the extent to which, regardless of the public access profile that might feature in the forest's status as greenspace, it would be a socionatural entity. All of this would fundamentally transform the sacred grove and, clearly, involve forest access to presumably nonParsi conservation professionals.

I agreed to meet the Doongerwadi forest steward for an introductory walk. Arranging our first meeting by phone, my host offered gracious but detailed instructions for how I should dress and conduct myself when I arrived. I was to wear loose and modest garments, and to be sure my arms and head were fully covered. I could bring a notebook, but other modes of recording or photographing what we discussed and witnessed were best left behind. I was to arrive at a side parking lot, and to wait for my host to escort me onto the grounds.

Our tour did not begin in the forest, at least according to the introductory narratives my host offered on my arrival. Instead, he pointed out and identified the complex of buildings at the entrance, devoted almost exclusively to the funerary purposes for which the Towers of Silence existed and for which the forest provided sonic and visual seclusion. We sat together while my host reviewed elements of the Zoroastrian philosophy of death and dying; he explained ideas of the soul, evil, pollution, and purification, and how the built structures that culminated in the Towers of Silence enabled the sanctity of those ideas through ritual. It was clear to 


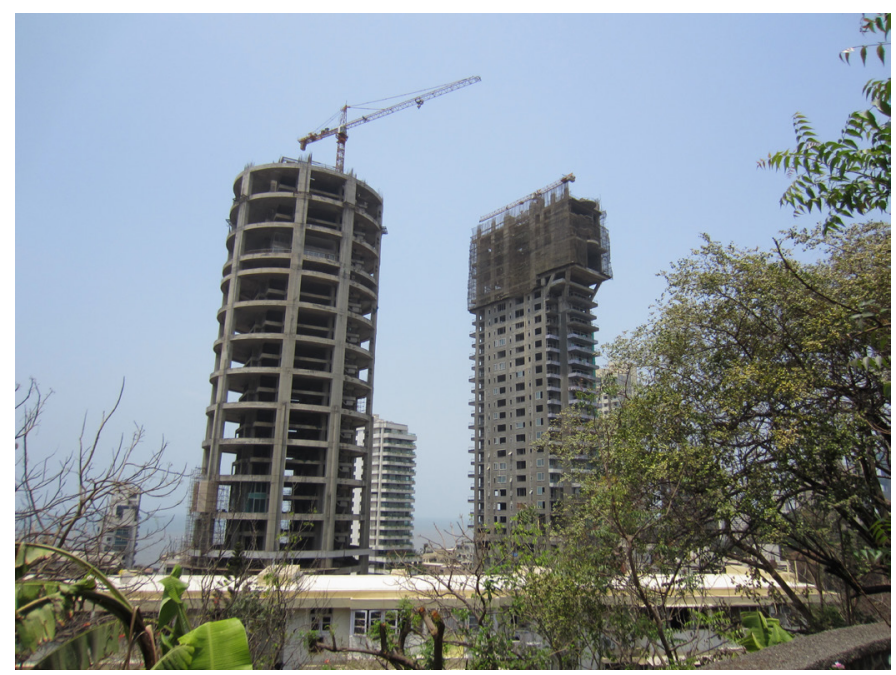

FIGURE 10. Looking outward from the edge of the Doongerwadi forest, new construction looms. Photo by the author.

me that for him, the forest that surrounded us was in every way a sacred grove; it was a buffer between the dense, clamorous, concrete city beyond it and the very separate ritual space that in many ways defined an entire religious community. In this sense, the forest made his idea of living and dying as a Parsi not only dignified, but possible.

Nevertheless, as the forest steward, my host was also keenly interested in walking me through the forest. We stayed far clear of the Towers, but I was warmly invited to see other aspects of the forest and complex. Eloquent in heavily Britishaccented English and highly educated, my host nevertheless explained that he had little background knowledge in basic forest ecology or management. Assuming the position of forest steward was something he did out of care for the history and preservation of the Doongerwadi complex, and so he described himself as an eager student of the forest. As we walked and talked through its use and management, we discussed basic processes of forest growth, regeneration, and decomposition. Many of the points were quite new to him, so our walk was also a lively question and answer session on elementary aspects of forest ecology.

As we made our way along wide but ever narrowing dirt paths, we walked through a forest of easily discernable patches. As one might expect, areas more frequently traversed in the course of funerary rites were largely covered in ornamental garden plants, with few trees that forest ecologists would identify as native. But beyond these areas of garden-style management, the patches told stories of different kinds of use, historical management attempts, and even the constant 
give-and-take of human community uses and non-human habitat. The stands were of different species mixes, age classes, and densities.

Early in the walk our conversation turned to forest history. It is well known that the Doongerwadi forest was originally significantly larger, and that a former forest section was developed for Parsi housing, at present-day Godrej Baug, in the 1970s. For decades afterward, high-rise development surrounding the remaining Doongerwadi influenced management strategies and forest use; my host told me that over thirty years ago a private high-rise apartment complex called the Grand Paradise was built to such a height that residents living on upper floors could see the funerary platform used for sky burial in one of the Towers. Complaints from those residents, my host told me, eventually led to the closure of the visible dokhma. Now, with a bit of anxiety, he pointed to multiple new high rises at various stages of construction all around the forest. "The super-rich who will live in them will surely have influence," he said, worried that they, too, would see the funerary platforms and register complaints. I recalled the proposed aviary netting, realizing that it would do more than keep vulture fledglings in; it would also provide a new layer of seclusion, as these additional high rises would challenge the seclusion capacity of the forest canopy alone. This seemed to intensify the urgency of discerning new narratives of value and scientific function for the Doongerwadi.

But the high rises to come were only part of the interconnected dynamics of the forest and urban construction. In several areas, we came upon clearings or discernibly younger, comparatively homogenous, forest stands. Each had a specific history that began with a dumping incident. Whether with or without formal permission, parts of the forest had served over many decades as secluded repositories for construction waste-plentiful in Mumbai, and often difficult to properly dispose. New to his position as Doongerwadi forest steward, my host said that the details of when and how each incident happened were unknown to him, and were in any case less important in the present than the fact that the forest management response usually involved covering over the rubble and planting it with whatever seemed like a good species choice at the time. Usually this meant a monocrop, often in an ornamental or otherwise resource-intensive vegetation type.

The mixed tropical Doongerwadi forest, then, had tucked within it a mosaic of stands, some ornamental, some of which forest ecologists would classify as "native" and some as "exotic." ${ }^{12}$ I remarked that this patchwork would make an interesting forest assessment challenge, mindful that in general, such patches fundamentally change forest structure, function, and biodiversity. To understand this specific mosaic, we clearly needed a forest ecologist or botanist.

Amid his urgent stories of forest threats, construction and development pressures, and the denuding effects of debris dumping, my host pointed to the elements of the forest he so clearly loved. Peafowl were all around us; he spoke of the existence of butterfly and plant species here that he was sure had otherwise 
disappeared from the Western Ghats. "We have them," he said with a mix of pride and admiration, "we just need an expert to verify their presence."

But as my host pointed to the forest elements that in his mind evidenced ill health, I realized that he and others charged with forest management also had some misconceptions about general forest ecology. He noted several dead tree branches and snags, for instance, asking if they would harm the forest and should be removed. When I explained that undiseased snags normally provide important habitat for birds, insects, and other animals, we realized together that these were potential assets, if a goal of forest management was to encourage biodiversity. Likewise, decomposing treefall that my host assumed should be removed because it might "spread disease" served as an opportunity to talk about how forest decomposition replenishes soil nutrients and ensures soil heath, and the general benefits of in situ decomposition in forests. Creepers in the forest canopy-which he had previously assumed to be harmful parasites_-might, I suggested, be benign and even beneficial. This was true as well for a termite mound we observed, and for a range of fungi growing on trees throughout Doongerwadi.

At the close of our walk, we agreed that a useful next step would be to identify a qualified botanist or forest scientist who could conduct a formal species inventory and forest health assessment. Like the proposed vulture breeding aviary, and even my own presence, such an assessment would require the community to give further permission to non-Parsis to access the Doongerwadi. This was granted, and the senior botanist and forest ecologist from the University of Mumbai who undertook the work was also a longstanding member of the affiliated faculty of Rachana Sansad Institute of Environmental Architecture. Although the Doongerwadi remained an extremely exclusive and unusual open space, the development and open space pressures of Mumbai's present brought even this otherwise closed forest into direct contact with RSIEA.

My core interest in considering the Doongerwadi encounter here is to return to the puzzle with which I opened the chapter. As popularly conceptualized, green or open space advocacy in Mumbai overwhelmingly assumed urban park-making to be its core task, in part because of a direct association between parks and social equity. It rarely addressed the possible desirability of a citywide range of vegetation types and coverage, or the different access, use, and socioecological profiles that each might enable. Yet when urban greening advocates sought to promote ideas for a more sustainable Mumbai, the attributes of that more desirable city often depended on the vitality of various ecosystem processes and functions. Many of these processes and functions occur only in vegetated areas with, for example, permeable surfaces or contiguous land cover patches sufficient to provide food, water, shelter, and space for non-humans.

Stated differently, in open spaces in which the human use scenario is relatively light or non-existent, such as in the fifty-four-acre closed canopy urban forest that is the Doongerwadi, certain biophysical processes are underway that may depend, 
in part, on the very fact of restricted human use. To advocate for the benefits those processes bestowed positioned the advocate in some ways against the equal access logics that underpin environmental justice assumptions. To complicate matters, Doongerwadi's existing exclusive use profile was predicated on a narrow, identitybased logic of exclusive access - a blatant and often pernicious form of social exclusion. The calculus of social and more-than-human loss and gain at work here defied the simpler metrics that often guided pervasive open space discourses.

Yet it also cast the Open Mumbai challenge, "How Would You Remake the City?" in an experiential light, challenging whether a comprehensive inventory of city green spaces and socioecological access profiles,could exist at all without creating or reinforcing social forms of marginality and exclusion.

Converging as it did with the peculiar bureaucratic temporality of a looming urban development plan deadline and the anxieties that attend impending, irreparable cultural and environmental loss, the Doongerwadi case thus sat at the unanticipated center of unresolved questions of what, precisely, the socionatural elements of green and open spaces $d o$, and what they might be intended to do, in the Mumbai of the future. Was social exclusion permissible if part of its organizing logic was open space preservation or creation? Could social exclusion be regarded as an acceptable cost of maintaining a nonhuman species on the very edge of extinction? Such questions have long histories in non-city spaces, of course; could they be reasonably posed in a city like Mumbai?

One way to engage this question is to note again that the very fact of my own presence in the Doongerwadi forest was the result of a strategy for discerning and re-narrating the multiple forms of value present there, critical aspects of a defensive stance against the dual threat posed by disappearing vultures and the forest's swelling real estate value. The speculative appeal of this land suggested the real dual loss: of the vultures, and with them, a centuries old funerary ritual at the center of religious identity production. Those who wished to maintain Parsi identity through the specific funerary ritual that the forest, vultures, and towers enabled were brought face to face with the extent to which the forest itself, through its provision of nonhuman habitat, had enabled the reproduction of that identity for centuries.

Yet the Doongerwadi's particular "save the forest" agenda seemed unable to claim a comfortable place in Mumbai's active open space politics, despite its potential to prevent building development in an otherwise vegetated area. Its necessarily highly exclusive access profile, combined with the specific cultural rituals to which its very existence was anchored, disqualified it from an imagined pool of potentially shared, accessible open spaces - the mosaic of green that comprised a more "open" Mumbai. The very open space category so active in the previous chapter not only presumed a generally homogenous quality to open space itself, but also to the broader suite of uses a given open space might serve. These uses were primarily "social" in the sense of human leisure and access. They were not social in the sense of explicit acknowledgement that social and cultural practices in specific 
urban open spaces might themselves delineate which human groups were entitled to access it, and which were necessarily excluded to preserve it.

If not immediately compatible with prevailing open space advocacy discourses, what place might the Doongerwadi assume in responsible visions of a reimagined Mumbai? After all, one of the forest steward's central goals was to better understand the range of ecological functions and forms of life this green space helped to enable. Was there truly a space for more-than-human nature in a future Mumbai that also aspired to ideals of equity, social justice, and "open" access?

In an era of climate change and popular demand for more sustainable cities, a standard answer to such a question is often expressed in terms of the biophysical ecosystem functions that can be quantitatively expressed as ecosystem services. ${ }^{13}$ Such services include, but are not limited to, energy and carbon dioxide conservation, often quantified as sequestration value; air quality improvement and maintenance; urban hydrology regulation (reducing the rate and volume of storm water runoff, mitigating flooding damage, reducing storm water treatment costs, and enhancing water quality); ecological stabilization through the provision of wildlife habitat, soil conservation, and biodiversity enhancement; and noise reduction. But these benefits accrue in different ways, in part depending on the characteristics of each urban green or open space. Ecologists often differentiate between them by assessing the level of disturbance, that is, the scale and frequency of human use, or other types of active management. ${ }^{14}$ Examples of such interventions include, but are not limited to, clearance of forest areas for leisure activity, use of forest areas for waste disposal (even if the waste is organic), removal of downed trees, ornamental pruning and other forms of aesthetic vegetation removal, and planting vegetation species with particular management objectives in mind. Chemical inputs like fertilizers and pesticides that might be commonly applied in more park-like settings with human heavy access and use scenarios constitute another significant intervention. Since very little management activity occurs in the Doongerwadi forest, in its urban context it is not just a rare, closed canopy, contiguous fifty-fouracre forest. It is also a low-disturbance urban forest. But the very vocabulary that considers human access and use as a disturbance sits uncomfortably at best within conventional frameworks of environmental justice. ${ }^{15}$

Popular advocacy for open space in Mumbai made noticeably little conceptual space for the desirability of low-disturbance urban forest; for one thing, the term disturbance itself seemed to underline the problem with exclusive access, since only certain users would qualify as "disturbers," while others would not. In the Doongerwadi, sacred grove status enabled some amount of cultural and identity justification for this, but even here its power was limited to members of the minority Parsi community or those who automatically valued biodiversity as a thing in itself, so defined and so coined. ${ }^{16}$

But if we take seriously the conceptual transformation from social exclusion to something that approaches more-than-human exclusion, we face an uneasy 
predicament: how can we advocate ecological resilience and social justice simultaneously? To foreground more-than-human-exclusion in the Doongerwadi case is in some ways to position a low-disturbance urban forest as espousing more value than its so-called high-disturbance, i.e., many kind of parks and counterparts. Lowdisturbance forests usually contain greater biological complexity and redundancy of forest functions, which usually leads to more and more functional ecosystem services, and resilience to a multitude of natural and anthropogenic stresses. It is also more likely that plant and animal species that ecologists would classify as native, along with greater general biodiversity, will be found in low-disturbance forests. Finally, a low-disturbance urban forest is potentially so valuable in ecological terms because of its structure: a mature, low-disturbance forest typically has a vertical forest structure that is stratified into dominants, canopy, sub-canopy, shrub, and groundstory layers. In each of these layers, vital and often interlocking ecosystem functions occur.

In short, if an expansive conceptualization of justice seeks simultaneous and legitimate places for human and more-than-human nature, the Doongerwadi forest could be framed as far more valuable as a closed access, minimally managed forest than any park that currently exists in the city, or, for that matter, that featured in the public exercises of "imagining" a desirable future Mumbai. Since ecologists often argue that broad ecosystem benefits, like a robust hydrological system that ensures clean and plentiful water, or vegetation that ensures clean air, accrue to everyone, they might also argue that a forest like Doongerwadi is extremely valuable to everyone in Mumbai whether or not they ever set foot in it, or even pass by. Indeed, the two characteristics-accessibility for leisure uses and optimal ecosystem service provision-often occupy two ends of the "open space" spectrum that this case brings to light.

A further obvious difficulty in the present case is that using its low disturbance/ ecosystem services value as the basis for saving the Doongerwadi from real estate development would likely result in a massive, and yet sanctioned as science, disturbance: the construction of an aviary intended to save the vultures and, just as in the case of the forest itself, the human life cycle ritual in which the vultures were indispensible. It was unclear at this writing whether and how the ecosystem services profile of the forest would change if the aviary were to be established.

To precisely define the ecosystem services and value of the Doongerwadi forest in accordance with the forest steward's request, a sense of the forest composition, structure, and dynamics was necessary. This involved completing a standard set of silvicultural assessments, typically called a forest inventory. The basic mapping of the types and abundance of flora and fauna species, as well as a maturity matrix (an assessment of which species are present in which age classes), were completed, all by the senior professor of botany and regular visiting lecturer at RSIEA mentioned above. It is here, perhaps, that we are reminded of one dimension of ecology in 
practice as it intersected with the concepts and techniques espoused in training settings at RSIEA. Good design, in this case, necessitated just such an inventory; it was only in an accounting of the built and unbuilt components of the site, and a clearer accounting of the larger scales and systems to which the latter were connected, that one could claim to have laid the necessary groundwork for integrated, good design thinking. And although it was not posed as such in this case, it is precisely integrated thinking that raises the question I conclude with here: what was the place of more-than-human nature in the future of the Doogerwadi, and how did humanity stand to lose and gain in its wake?

Once the professor's reports were filed, it was possible to specify the Doongerwadi's conservation value in more precise scientific terms. Species richness, functional groups, and species traits like rarity could all be determined, and from these, certain monetary values could be derived through ecosystem services calculations. Consistent with the forest steward's wishes, a new way of knowing, and conveying, the Doongerwadi's value could now be articulated.

This returns us to the limited utility of our existing analytics when it comes to social analyses of urban greening. Recall that on one hand, a wealth of studies explore how the opportunity to "green" a city, and to engage in singular and collective exercises that rethink the relationship between humans and nonhuman nature within them, is often analyzed in terms of its potential to promote or reproduce notions of civility and citizenship, empowerment, political praxis, and the desirable place and form of "nature" in the city. Another cluster of work outlines the exclusionary and often violent ways that urban greening is operationalized, pointing to the marginalities that park-making can recreate or newly produce.

We note in this case that it is important to avoid the analytical conflation of parks and ecology, even when this conflation is restated as an ethnographic fact. The relationship between city green spaces and the ecological systems in which they nest-in the present case, for example, forest ecology_suggests an analytical imperative to remain attuned to the extent to which green space politics and their agents do or do not promote a continuum of human use and management scenarios intended to maximize the attributes that, for lack of a more robust analytic, I have indexed here through the rubric of ecosystem services. Yet the life and death stakes of the Doongerwadi case are simultaneously biophysical and social, and we are poised to miss these dimensions if we undertake a more typical assessment of the ratio of open spaces to a city's human population.

Similarly, when political ecologists describe the multiple "ways of knowing nature" that characterize any contest over the environment, ${ }^{17}$ we have historically demonstrated the ways that science has claimed relative power and dominance, leaving us compelled to amplify other social experiences and narrations of nature as equally situated and legitimate "alternatives." But the present case forces a careful assessment of that stance; the Doongerwadi forest steward undertook a scientific assessment as just one in a range of strategies for maintaining the forest, 
its related non-human species, and in so doing reviving the religious rituals performed therein. The alternative bundle of values that the forest assessment was intended to enable did not constitute an overt call to elevate the scientific characterization of the forest over other formulations, or to bring back long discredited modes of conservation that sought to establish clear boundaries between territories for (nonhuman) nature and places for people. But it was-like the forest steward's own gesture of welcome to me-a layered attempt to develop and operationalize a fuller knowledge and experience of more-than-human urban nature, in part in service of mutually reproduced human and nonhuman lifeways.

In a now classic piece, the political ecologist Nick Heynen addressed a quandary similar to the one the Doongerwadi case compels us to consider in another guise: noting what he called "the production of injustice" in urban forestry, he argued that while environmental justice movements tended to demand universal and equal access to the benefits of the urban forest, "the resulting distributed urban forest may not address global environmental concerns as effectively as the larger forest islands that have resulted from uneven development." 18 The vultures, rituals, and towers of the Doongerwadi show how Heynen's quandary, which he framed in terms of global and local is, in fact, also evident at the city scale, and would certainly characterize the city-countryside continuum. The problem of demand for "equal access" is also one of nature-making itself; it risks leaving out a wealth of species, habitats, and systems on which the humans who seek access to those spaces may fundamentally depend.

If integrative, good design thinking compelled agents of environmental architecture and other urban environmental professions to promote optimal ecosystem vitality, then the Doongerwadi case also raises questions of how, when, and why differently positioned social actors deem it appropriate to create and maintain green spaces that are largely socially exclusive. The challenge, quite simply, is to extend the social justice imperative of inclusion and equity beyond human beings themselves. This challenge is, after all, inseparable from those presented by unequal social power relations, ideologies of belonging, and human social identity construction, but it is also inseparable from the logics through which human social groups select which aspects of non-human nature thrive, and which meet their demise. As the fate of the vultures reminds us, the two are inevitably and inexorably interconnected. The environment, as Dr. Joshi explained earlier in the book, is indeed an "integrated subject."

If the agents of RSIEA, in this case the professor who undertook the Doongerwadi forest assessment, reconnect contests over Mumbai's future open spaces to the active making and dissemination of ideas and practices of good deisgn at RSIEA, then the politics that good design thinking constructed warrant more careful attention. We return, then, in the next chapter, to the making of a collective moral ecology through the curricular experience at Rachana Sansad Institute for Environmental Architecture. 